\title{
In Vitro Starch Digestibility, Rheological, and Physicochemical Properties of Water Caltrop Starch Modified with Cycled Heat-Moisture Treatment
}

\author{
Po-Ching Tsai and Lih-Shiuh Lai *(D) \\ Department of Food Science and Biotechnology, National Chung Hsing University, 145 Xingda Road, \\ Taichung 40227, Taiwan; ss40616ss@gmail.com \\ * Correspondence: lslai@dragon.nchu.edu.tw
}

check for updates

Citation: Tsai, P.-C.; Lai, L.-S. In Vitro Starch Digestibility, Rheological, and Physicochemical Properties of Water Caltrop Starch Modified with Cycled Heat-Moisture Treatment. Foods 2021, 10, 1687. https://doi.org/10.3390/ foods10081687

Academic Editors

Grazyna Lewandowicz and

Wioletta Błaszczak

Received: 23 June 2021

Accepted: 19 July 2021

Published: 21 July 2021

Publisher's Note: MDPI stays neutral with regard to jurisdictional claims in published maps and institutional affiliations.

Copyright: (c) 2021 by the authors. Licensee MDPI, Basel, Switzerland. This article is an open access article distributed under the terms and conditions of the Creative Commons Attribution (CC BY) license (https:// creativecommons.org/licenses/by/ $4.0 /)$

\begin{abstract}
This study focused on the effect of cycled heat-moisture treatment (cHMT) on the in vitro digestibility, rheological, and physicochemical properties of water caltrop starch. The amylose content increased significantly by cHMT, whereas damaged starch content decreased only in the groups with more than two cycles applications. cHMT generally increased the weight-average molecular weight, except for single cycle treatment which showed the reverse result. In thermal properties, the onset temperature $\left(T_{0}\right)$, peak temperature $\left(T_{p}\right)$, and conclusion temperature $\left(T_{c}\right)$ increased, while the enthalpy needed to complete the gelatinization was lowered by cHMT. Water caltrop starch paste showed less shear-thinning behavior with cHMT. Meanwhile, the viscosity and tendency to form strong gel were enfeebled with modification. cHMT significantly changed predicted glycemic index (pGI) value, especially in samples that underwent the most cycles of treatment, which showed the lowest pGI compared to native and other treatment. These results suggested that cHMT water caltrop starch was effectively modified and showed diversified properties.
\end{abstract}

Keywords: starch modification; rheological properties; predicted glycemic index

\section{Introduction}

Water caltrops (Trapa taiwanensis Nakai) are aquatic crops cultivated in shallow water ponds especially in Southern Taiwan. The kernels are mainly composed of starch and can reach a maximum content of $79.4 \%$ (d.b.) during growth [1,2]. Water caltrop starch showed higher onset temperature $\left(T_{0}\right)$, peak temperature $\left(T_{p}\right)$, and conclusion temperature $\left(T_{c}\right)$ than corn and potato starch [3] and four aquatic vegetables in China [4]. It also showed solid-gel characteristics and dynamic rheological properties [5]. In other research, water caltrop also showed a great amount of resistant starch and a number of nutritional benefits; hence, water caltrops have been cultivated for years as food or traditional medicine in India and China $[6,7]$.

Starch is a widely used material in the food industry. For example, it is used as a stabilizer [8], fat replacer [9], or versatile additive [10] in yogurt, baked goods, instant soups, sauces, and meat sausages [11]. However, native starch has some limitations in application due to its low heat stability, low shear resistance, and tendency to retrogradate. Starch has an essential role in nourishment and daily supplements of energy. According to the rate of digestion and glucose content released, predicted glycemic index (pGI) can be acquired by dividing the incremental postprandial blood glucose released from the samples by that of reference sample. Generally, lower GI is seen as a positive for patients with low glucose tolerance [12]. Hence, to fulfill these requirements, much research has modified starch with chemical, physical, and enzymatic techniques [13] to provide unique starch characteristics with better thermal stability, mechanical stability [14-16], and digestibility [17].

Heat-moisture treatment (HMT) is one of the widely used approaches to physically modifying the properties of starch [18]. The advantages of HMT include fewer toxic effects, 
and the procedure is generally considered as safe. Furthermore, several studies have shown that HMT provides significant benefits to physicochemical properties, rheological properties, and digestibility [19-22]. Aside from single HMT, other researchers also tested the effect of multiple cycles of HMT and concluded that repeated modifications were capable of enhancing the gelatinization temperature, crystallinity, and digestibility of sweet potato starch [23], wheat starch [24], corn starch, tapioca starch, and potato starch [15,25].

Although single and multiple HMT have exhibited promising effects on physicochemical properties and digestibility in many studies [11,26,27], few studies have examined the effect of cycled heat-moisture treatment on water caltrop starch. A previous study reported that HMT showed significant influence on physicochemical and digestibility of water caltrop starch [28]. Therefore, we assumed that cycled heat-moisture treatment may exert more pronounced effects on water caltrop starch in comparison to a single cycle of HMT. To examine our hypothesis, we tested the effect of cycled heat-moisture treatment on the in vitro digestibility, rheological properties, and physicochemical properties of water caltrop starch.

\section{Materials and Methods}

\subsection{Materials}

Water caltrops (Trapa taiwanensis Nakai) were cultivated and harvested in Tainan, Taiwan. The $\alpha$-amylase, amyloglucosidase, amylose kit, and damaged starch kit were purchased from Megazyme (Megazyme International Ireland, Co. Wicklow, Ireland). All chemical substances applied in this study were of analytical grade.

\subsection{Starch Isolation}

The extraction of starch was applied in accordance with a previous report with slight modifications [29]. In the typical extraction, the fresh kernels of water caltrop were blended with twice the volume of distilled water and mixed with $0.2 \%(w / v)$ sodium hydroxide solution. The mixture was placed at $4{ }^{\circ} \mathrm{C}$ for $12 \mathrm{~h}$; thereafter, the upper brown liquid was decanted, and the starch precipitate was washed with distilled water and left to precipitate. The washing process was repeated until the starch was clean and the $\mathrm{pH}$ value of starch dispersion reached neutral. After removing the impurities, the starch pellet was dried at $40{ }^{\circ} \mathrm{C}$ for $72 \mathrm{~h}$, ground, passed through a 100-mesh sieve, and stored at room temperature. The unmodified starch was designated as Native-S.

\subsection{Cycled Heat Moisture Treatment}

A previous method was applied including some modifications [30]. The moisture level of water caltrop starch was adjusted to $20 \%$ by adding adequate distilled water. The mixtures were stirred, sealed in the tinplate cans, and modified by cycled heat-moisture treatment (cHMT) at $105{ }^{\circ} \mathrm{C}$ with different cycles. The total heating time for each sample was $16 \mathrm{~h}$; however, the heating time was divided into 1 cycle (16 h/cycle), 2 cycles ( $8 \mathrm{~h} /$ cycle), 4 cycles $(4 \mathrm{~h} /$ cycle), and 8 cycles $(2 \mathrm{~h} /$ cycle), with $30 \mathrm{~min}$ of cooling at room temperature between each heating procedure. The cycling numbers of 1, 2, 4, and 8 were designated as cHMT1, cHMT2, cHMT4, and cHMT8, respectively. The modified samples were dried at $40{ }^{\circ} \mathrm{C}$ until the moisture level reached approximately $10 \%$ then milled and screened through a 100-mesh sieve and stored at room temperature.

\subsection{Amylose and Damaged Starch Content}

The amylose and damaged starch content of water caltrop starch was determined by using a Megazyme amylose kit (K-AMYL) and a damaged starch kit (K-SDAM), respectively, with the procedures recommended by the manufacturer.

\subsection{Molecular Weight Distribution}

The molecular weight distribution profile of water caltrop starch was evaluated by gel permeation chromatography (GPC) using a column $(2.6 \times 90 \mathrm{~cm}$ diameter/height) packed 
with Sepharose CL-2B agarose gel. Sample preparation was according to a method from previous research [31]. A $5 \mathrm{~mL}$ aliquot including $15 \mathrm{mg}$ of starch and glucose marker was injected in the column and underwent elution in the ascending mode. The eluting buffer contained $25 \mathrm{mM} \mathrm{NaCl}, 1 \mathrm{mM} \mathrm{NaOH}$, and $0.02 \% \mathrm{NaN} 3$ and had a flow rate of $30 \mathrm{~mL} / \mathrm{h}$. Fractions of 100 tubes were collected ( $5 \mathrm{~mL} /$ tube), and total sugar content was measured using the phenol-sulfuric acid method at $490 \mathrm{~nm}$, while iodine-stained blue value was measured at $630 \mathrm{~nm}$. The standard curve was made of dextran with different molecular weights prepared with a similar method to that mentioned above. The weight-average molecular weight was calculated:

$$
\overline{\mathrm{Mw}}=\frac{\Sigma \mathrm{Mi} \times \mathrm{Ci}}{\Sigma \mathrm{Ci}}
$$

In Equation (1), $\mathrm{Mi}$ is the molecular weight at ith fraction, and $\mathrm{Ci}$ is the glucose concentration at ith fraction $(\mu \mathrm{g} / \mathrm{mL})$.

\subsection{Thermal Properties}

Thermal properties of water caltrop starch were measured by using differential scanning calorimetry (DSC 1 STAR system, Mettler Toledo, Switzerland) according to the previous method [19]. Samples were prepared by mixing $10 \mathrm{mg}$ of starch with $40 \mathrm{mg}$ of pure water. The mixtures were then vigorously shaken to disperse the starch evenly. Then, $6 \mathrm{mg}$ of the mixture was instantly transferred into an aluminum crucible using a pipette. The crucibles were sealed hermetically and stored at $4{ }^{\circ} \mathrm{C}$ for $24 \mathrm{~h}$ before analysis. The measurement involved heating from 25 to $95^{\circ} \mathrm{C}$ at a rate of $10^{\circ} \mathrm{C} / \mathrm{min}$. Then, the onset temperature $\left(\mathrm{T}_{0}\right)$, peak temperature $\left(\mathrm{T}_{\mathrm{p}}\right)$, conclusion temperature $\left(\mathrm{T}_{\mathrm{c}}\right)$, and gelatinization enthalpy $(\Delta \mathrm{H})$ were recorded during the heating process.

\subsection{Steady Shear Rheological Measurement}

Steady shear properties were measured according to the previous method [32] with a rheometer (MCR92, Anton Paar, Graz, Austria). The starch paste $(6 \%, w / w)$ was prepared by using RVA (RVA-Ezi, Newport Scientific Pty. Ltd., Warriewood, Austria) at a rotation speed of $160 \mathrm{rpm}$, heated from 50 to $95^{\circ} \mathrm{C}$ for $3.5 \mathrm{~min}$, and held at $95^{\circ} \mathrm{C}$ for $3 \mathrm{~min}$ for full gelatinization. Then, the starch sample was rapidly poured into a rotational concentric cylinders, equilibrated at $25^{\circ} \mathrm{C}$ for 3 min before analysis, and continuously sheared in the gap $(0.099 \mathrm{~mm}$ ) between the inner cylinder (radius: $26.652 \mathrm{~mm}$, length: $39.999 \mathrm{~mm}$ ) and the outer cylinder (radius: $28.922 \mathrm{~mm}$ ) from shear rate of 1 to $100 \mathrm{~s}^{-1}$. Herschel-Bulkley model was applied to describe the flow behavior of the samples at steady shear:

$$
\sigma=\sigma_{0}+K(\dot{\gamma})^{n}
$$

In Equation (2), $\sigma$ is the shear stress (Pa), $\sigma_{0}$ is the yield stress (Pa), $\mathrm{K}$ is the consistency index $\left(\operatorname{Pa} . \mathrm{s}^{\mathrm{n}}\right), \dot{\gamma}$ is the shear rate $\left(\mathrm{s}^{-1}\right)$, and $n$ is the flow behavior index (dimensionless).

\subsection{Dynamic Rheological Properties}

The dynamic properties of water caltrop starch were measured using the same rheometer equipped with a parallel plate (diameter: $50.00 \mathrm{~mm}$ ) and with a $1 \mathrm{~mm}$ gap using the previous method with slight modifications [32]. Meanwhile, the samples were prepared using RVA similar to the method described in steady shear measurement. The starch paste was sheared in the range of 0.1 to $100 \mathrm{rad} / \mathrm{s}$ at $1 \%$ strain, which was in the linear viscoelastic region. The storage modulus $\left(\mathrm{G}^{\prime}\right)$, loss modulus $\left(\mathrm{G}^{\prime \prime}\right)$, and loss tangent $(\tan \delta)$ were measured at $25^{\circ} \mathrm{C}$.

\subsection{In Vitro Digestibility and Predicted Glycemic Index of Cooked Starch}

The in vitro kinetics and predicted glycemic index were inspected with the method reported previously $[33,34]$ with slight modifications. Starch samples (100 $\mathrm{mg}$, dry basis) 
were mixed with $2.5 \mathrm{~mL}$ of distilled water and cooked in boiling water for $10 \mathrm{~min}$ with continuous stirring by magnetic bars. Then, $2 \mathrm{~mL}$ of sodium maleate buffer $(100 \mathrm{mM}, \mathrm{pH} 6.0$ with $2 \mathrm{mM}$ calcium chloride) was immediately added, and samples were incubated at $37^{\circ} \mathrm{C}$ for $5 \mathrm{~min}$ in a shaking water bath. Next, $2 \mathrm{~mL}$ of pancreatic $\alpha$-amylase (93.75 Ceralpha unit $/ \mathrm{mL}$ ) and amyloglucosidase $(9.375 \mathrm{U} / \mathrm{mL})$ was added and incubated at $37^{\circ} \mathrm{C}$ with shaking ( $200 \mathrm{rpm}$ ) for digestion. Aliquots of $0.08 \mathrm{~mL}$ hydrolyzed solution were taken at 5 , $10,20,40,80,120$, and $180 \mathrm{~min}$, respectively. The aliquots were mixed with $0.64 \mathrm{~mL}$ of $95 \%$ ethanol solution to inactivate the enzymes. The glucose content of $0.1 \mathrm{~mL}$ hydrolysates was evaluated by a Megazyme D-Glucose Assay Kit (GOPOD) containing glucose oxidase and peroxidase solution. The hydrolysis percentage was calculated as described:

$$
\frac{\mathrm{Gt} \times \frac{0.72}{0.1} \times \frac{6.5}{0.08} \times 10^{-3} \times 0.9}{100} \times 100
$$

In Equation (3), Gt is the glucose concentration $(\mu \mathrm{g} / 0.1 \mathrm{~mL})$ at time $\mathrm{t}$. The curve of enzyme hydrolysis followed a first-order equation. For reference, dried white toast was used. The calculation of predicted glycemic index followed the equations:

$$
\begin{gathered}
\mathrm{HP}=\mathrm{HP}_{\infty} \times\left(1-\mathrm{e}^{-\mathrm{kt}}\right), \mathrm{HP}_{\infty} \leq 100 \% \\
\text { Area under curve }(\mathrm{AUC})=\int_{0}^{180} \mathrm{HP}_{\infty} \times\left(1-\mathrm{e}^{-\mathrm{kt}}\right) \mathrm{dt} \\
\text { Hydrolysis index }(\mathrm{HI})=\frac{\mathrm{AUC}_{\text {samples }}}{\mathrm{AUC} \text { reference }} \\
\text { Predicted glycemic index }(\mathrm{pGI})=39.71+0.549 \times(\mathrm{HI})
\end{gathered}
$$

In Equations (4)-(7), HP is the hydrolysis percentage at time $t, \mathrm{HP}_{\infty}$ is the equilibrium hydrolysis percentage, $\mathrm{k}$ is the kinetic constant, $\mathrm{t}$ is the chosen time, $\mathrm{AUC}_{\text {samples }}$ is the area under curve of samples, and $\mathrm{AUC}_{\text {reference }}$ is the area under curve of the reference white bread.

\subsection{Statistical Analysis}

The measurements were performed in triplicate, and the data were analyzed with one-way analysis of variance (ANOVA) followed by Duncan's multiple range test with SPSS 20.0 at a significance level of $95 \%(p<0.05)$.

\section{Results and Discussion}

\subsection{Amylose and Damaged Starch Content}

As shown in Table 1, the amylose content was significantly influenced by cHMT. Native water caltrop starch (Native-S) contained $25.01 \%$ amylose, which is similar to previous results for water caltrop starch [1,35]. However, after modification, the amylose content significantly increased, and this can be explained by the breakage of side chains of amylopectin [36]. Heat-moisture treatment provided energy to cleave the $\alpha-1,6$ glycosidic bond in the amorphous regions and caused the sides chains of amylopectin to break and turn into small fractions of amylose and increase the amylose content.

The damaged starch content of water caltrop starch showed no significant difference at Native-S, cHMT1-S, and cHMT2-S. However, when more cycles were applied (cHMT4-S and cHMT8-S), the damaged starch content significantly lowered. This was possibly due to the accelerated recrystallization during cHMT, which enhanced the resistance to the tested enzymes and reduced the damaged starch content [37]. These results were in line with other studies on mung bean starch, potato starch, corn starch, and waxy corn starch, which showed reduced damaged starch content after heat-moisture treatment [38]. 
Table 1. Amylose content and damaged starch content of native and cHMT samples ${ }^{1,2}$.

\begin{tabular}{ccc}
\hline Treatment & Amylose Content (\%, d.b.) & Damaged Starch Content (\%, d.b.) \\
\hline Native-S & $25.01 \pm 0.70^{\mathrm{a}}$ & $1.26 \pm 0.04^{\mathrm{a}}$ \\
cHMT1-S & $26.16 \pm 0.36^{\mathrm{bc}}$ & $1.25 \pm 0.01^{\mathrm{a}}$ \\
cHMT2-S & $25.42 \pm 0.61^{\mathrm{ab}}$ & $1.29 \pm 0.11^{\mathrm{a}}$ \\
cHMT4-S $^{\mathrm{c}}$ & $26.37 \pm 0.17^{\mathrm{c}}$ & $0.61 \pm 0.06^{\mathrm{b}}$ \\
cHMT8-S & $26.06 \pm 0.20^{\mathrm{bc}}$ & $0.34 \pm 0.01^{\mathrm{c}}$ \\
\hline
\end{tabular}

${ }^{1}$ Data presented are in mean \pm SD form $(n=3)$; different letters in the same column indicate the significant difference at $p<0.05 .{ }^{2}$ The capital $S$ indicates water caltrop starch, and the number indicates the cycles in cHMT.

\subsection{Molecular Weight Distribution}

Gel permeation chromatograms of native and cHMT water caltrop starch are presented in Figure 1. The first peak correlated to amylopectin, the second peak with considerable blue value correlated to amylose, and the last peak was the glucose marker. In cHMT1-S, the peak of amylopectin apparently decreased, resulting in lower weight-average molecular weight. The reduction of the amylopectin peak was attributed to the excessive heat provided by the single cycle of modification, which disrupted the double helices in the amorphous region and broke the sidechain of amylopectin into small fractions of amylose [39]. A previous report on heat-moisture treated breadfruits showed similar reductions in amylopectin peak and weight-average molecular weight with a heat-moisture treatment [30]. However, in cHMT2-S, cHMT4-S, and cHMT8-S (multiple cycles applied), the weight-average molecular weight increased up to $1.60 \times 10^{9}$. This may be explained by enhanced retrogradation of starch molecules in repeated cooling procedures, which prompted the interaction of amylopectin [40]. Hence, amylopectin with larger molecular weight was increased and led to higher weight-average molecular weight $[41,42]$.
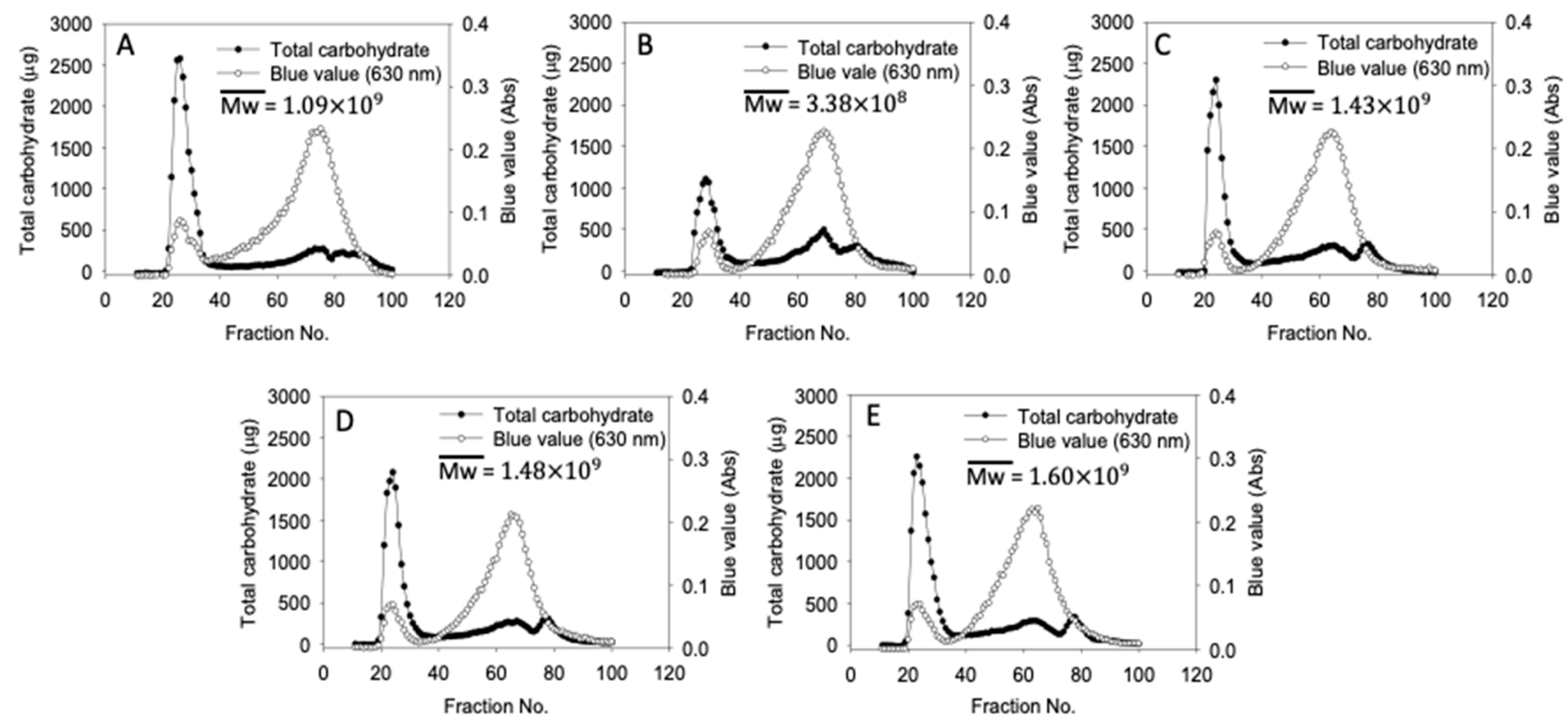

Figure 1. Starch molecular size distribution of water caltrop starch. (A) Native-S, (B) cHMT1-S, (C) cHMT2-S, (D) cHMT4-S, (E) cHMT8-S.

\subsection{Thermal Properties}

As shown in Table 2, the thermal properties of water caltrop starch were changed significantly by cHMT. Higher $\mathrm{T}_{0}, \mathrm{~T}_{\mathrm{p}}$, and $\mathrm{T}_{\mathrm{c}}$ were observed in cHMT water caltrop starch; this was possibly related to higher amylose content, which resulted in more interactions between the starch molecules. Therefore, a higher temperature would be needed to disrupt the order of starch granules [43]. cHMT included repeated cycles of heating and cooling, which facilitated the rearrangement of starch molecules. As a result, more compact struc- 
tures were formed and hindered the transfer of heat during DSC examination. These results were similar to the behavior of multi-cycled heat-moisture treated azuki bean starch [44], sweet potato starch [23], and wheat starch [45]. cHMT2-S, cHMT4-S, and cHMT8-S with more than one cycle of $c H M T$ showed higher and similar $\mathrm{T}_{\mathrm{p}}$ with no significant difference, indicating their similarity and better heat stability after cHMT. The decrement of $\Delta \mathrm{H}$ may be due to lower amylopectin content, which contributed to fewer double helices inside the crystalline domain and lower enthalpy acquired for gelatinization [46].

Table 2. Thermal properties of native/cHMT samples ${ }^{1,2}$.

\begin{tabular}{cccccc}
\hline Treatment & $\mathbf{T}_{\mathbf{0}}\left({ }^{\circ} \mathbf{C}\right)$ & $\mathbf{T}_{\mathbf{p}}\left({ }^{\circ} \mathbf{C}\right)$ & $\mathbf{T}_{\mathbf{c}}\left({ }^{\circ} \mathbf{C}\right)$ & $\mathbf{T}_{\mathbf{c}}-\mathbf{T}_{\mathbf{0}}\left({ }^{\circ} \mathbf{C}\right)$ & $\Delta \mathbf{H}(\mathbf{J} / \mathbf{g})$ \\
\hline Native-S & $77.38 \pm 0.40^{\mathrm{a}}$ & $81.18 \pm 0.10^{\mathrm{a}}$ & $85.77 \pm 0.54^{\mathrm{a}}$ & $8.39 \pm 0.93^{\mathrm{a}}$ & $4.41 \pm 0.57^{\mathrm{b}}$ \\
cHMT1-S & $82.61 \pm 0.29^{\mathrm{b}}$ & $87.35 \pm 0.33^{\mathrm{b}}$ & $94.83 \pm 0.73^{\mathrm{bc}}$ & $12.22 \pm 0.44^{\mathrm{d}}$ & $3.35 \pm 0.20^{\mathrm{a}}$ \\
cHMT2-S & $83.66 \pm 0.51^{\mathrm{c}}$ & $88.89 \pm 0.45^{\mathrm{c}}$ & $95.30 \pm 0.33^{\mathrm{c}}$ & $11.34 \pm 0.21^{\mathrm{cd}}$ & $3.39 \pm 0.11^{\mathrm{a}}$ \\
cHMT4-S $^{\mathrm{c}}$ & $83.21 \pm 0.14^{\mathrm{c}}$ & $88.54 \pm 0.09^{\mathrm{c}}$ & $94.41 \pm 0.08^{\mathrm{b}}$ & $11.20 \pm 0.18^{\mathrm{c}}$ & $3.74 \pm 0.05^{\mathrm{a}}$ \\
cHMT8-S & $84.32 \pm 0.18^{\mathrm{d}}$ & $88.69 \pm 0.20^{\mathrm{c}}$ & $94.32 \pm 0.17^{\mathrm{b}}$ & $10.00 \pm 0.12^{\mathrm{b}}$ & $3.76 \pm 0.06^{\mathrm{a}}$ \\
\hline
\end{tabular}

${ }^{1}$ Data presented are in mean $\pm \mathrm{SD}$ form $(n=3)$; different letters in the same column indicate the significant difference at $p<0.05 .{ }^{2}$ The capital $\mathrm{S}$ indicates water caltrop starch, and the number indicates the cycles in cHMT.

\subsection{Steady Shear Rheological Measurement}

The curves of steady shear measurement of native and cHMT water caltrop starch pastes are presented in Figure 2. The viscosity decreased with increasing shear rate; this implied that water caltrop starch paste behaved as a non-Newtonian fluid. A similar result was also found in Kunth root starch [47].
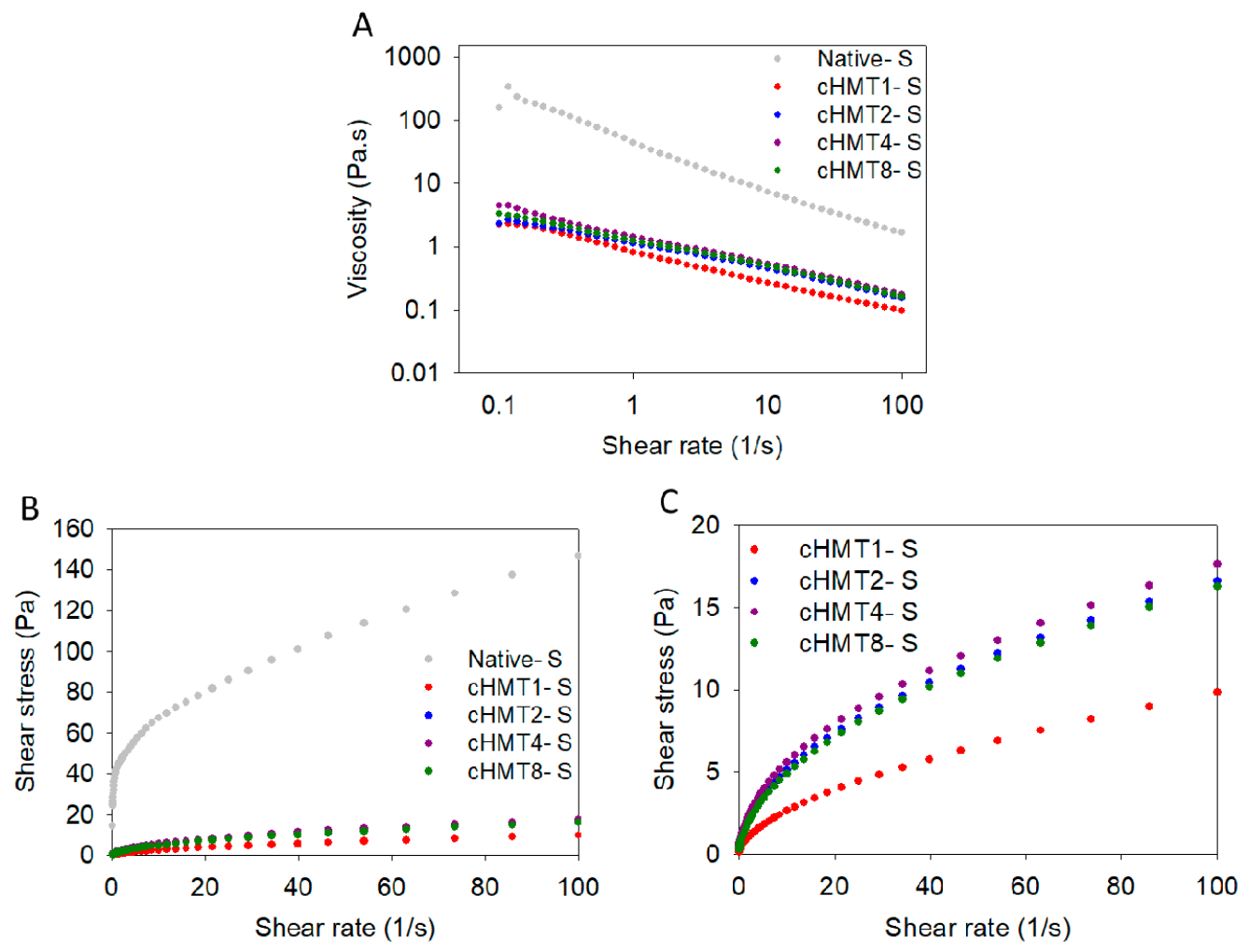

Figure 2. Steady shear rheological properties of native and cHMT water caltrop starch paste. (A) Viscosity versus shear rate. (B) Shear stress versus shear rate of native and cHMT starch. (C) Shear stress versus shear rate of cHMT starch.

The parameters of the Herschel-Bulkley model used to describe the flow curves are presented in Table 3. It was found that the determination coefficients $\left(R^{2}\right)$ of each sample 
ranged from 0.968 to 0.999 , suggesting that the Herschel-Bulkley model fitted well to the profile of rheological characteristics. The flow behavior index $(n)$ reflects the similarity to Newtonian fluid; $n=1$ equals Newtonian fluid and a lower value of $n$ indicates a higher degree of shear-thinning properties. Both native and cHMT samples showed $n$ values of less than 1.0, implying that water caltrop starch pastes exhibited shear-thinning behavior. Furthermore, with increasing cycles of cHMT, the $n$ value also increased progressively, indicating that cHMT samples showed less shear-thinning behavior. The K value and $\sigma_{0}$ could be considered as the gel viscosity and stress to initiate the flow, respectively [48]. Compared to Native-S, modified water caltrop starch showed lower values of $\mathrm{K}$ and $\sigma_{0}$, indicating that modified starch had lower viscosity and required less stress to start the flow.

Table 3. Herschel-Bulkley model parameters of native and cHMT water caltrop starch ${ }^{1,2}$.

\begin{tabular}{lcccc}
\hline Treatment & $\boldsymbol{\sigma}_{\mathbf{0}} \mathbf{( P a )}$ & $\boldsymbol{n}$ & $\mathbf{K}_{\mathbf{( P a . s}} \mathbf{s}^{\mathbf{n}}$ & $\mathbf{R}^{\mathbf{2}}$ \\
\hline Native-S & $17.290 \pm 0.880^{\mathrm{b}}$ & $0.380 \pm 0.016^{\mathrm{a}}$ & $21.006 \pm 0.885^{\mathrm{b}}$ & 0.968 \\
cHMT1-S & $0.032 \pm 0.018^{\mathrm{a}}$ & $0.569 \pm 0.072^{\mathrm{b}}$ & $1.466 \pm 0.024^{\mathrm{a}}$ & 0.994 \\
cHMT2-S & $0.196 \pm 0.036^{\mathrm{a}}$ & $0.604 \pm 0.020^{\mathrm{b}}$ & $1.178 \pm 0.036^{\mathrm{a}}$ & 0.995 \\
cHMT4-S & $0.237 \pm 0.068^{\mathrm{a}}$ & $0.647 \pm 0.022^{\mathrm{c}}$ & $1.099 \pm 0.107^{\mathrm{a}}$ & 0.993 \\
cHMT8-S & $0.081 \pm 0.015^{\mathrm{a}}$ & $0.655 \pm 0.029^{\mathrm{c}}$ & $1.131 \pm 0.069^{\mathrm{a}}$ & 0.996 \\
\hline
\end{tabular}

${ }^{1}$ Data presented are in mean \pm SD form $(n=3)$; different letters in the same column indicate the significant difference at $p<0.05 .{ }^{2}$ The capital S indicates water caltrop starch, and the number indicates the cycles in cHMT.

\subsection{Dynamic Rheological Properties}

The storage modulus $\left(G^{\prime}\right)$ is the amount of deformation energy stored in the sample during shear, and it represents the elasticity of the sample. In contrast, the loss modulus $\left(G^{\prime \prime}\right)$ is the amount of deformation energy consumed during shear and represents the viscosity of the sample [48]. The ratio of $G^{\prime \prime} / G^{\prime}$ is called the loss tangent $(\tan \delta)$, which can identify the viscoelastic properties of the gel. As shown in Figure 3, the storage modulus $\left(G^{\prime}\right)$ was significantly higher than the loss modulus $\left(G^{\prime \prime}\right)$ in water caltrop starch and indicated that all samples show solid-like characteristics.

After modification, the $G^{\prime}$ and $G^{\prime \prime}$ values were gradually reduced as the number of cycles decreased, and the parameters are shown in Table 4 . This result was similar to the previous findings [48], which reported that heat-moisture treatment encouraged the deformability of starch granules and hindered the formation of strong gel structures. But cHMT8-S, which was treated with the most cycles showed a higher value compared to other groups, indicating the milder modification and better similarity to Native-S.

Table 4. Viscoelastic properties of native and cHMT water caltrop starch at $6.28 \mathrm{rad} / \mathrm{s}^{1,2}$.

\begin{tabular}{cccc}
\hline Treatment & $\mathbf{G}^{\prime}(\mathbf{P a})$ & $\mathbf{G}^{\prime \prime}(\mathbf{P a})$ & $\tan \delta$ \\
\hline Native-S & $1401.833^{\mathrm{d}}$ & $54.867^{\mathrm{d}}$ & $0.039^{\mathrm{a}}$ \\
cHMT1-S & $244.087^{\mathrm{a}}$ & $17.365^{\mathrm{a}}$ & $0.072^{\mathrm{c}}$ \\
cHMT2-S & $458.467^{\mathrm{b}}$ & $19.179^{\mathrm{b}}$ & $0.042^{\mathrm{ab}}$ \\
cHMT4-S & $589.353^{\mathrm{c}}$ & $30.221^{\mathrm{c}}$ & $0.052^{\mathrm{ab}}$ \\
cHMT8-S & $626.350^{\mathrm{c}}$ & $34.500^{\mathrm{c}}$ & $0.055^{\mathrm{b}}$ \\
\hline
\end{tabular}

${ }^{1}$ Data presented are in mean \pm SD form $(n=3)$; different letters in the same column indicate the significant difference at $p<0.05 .{ }^{2}$ The capital $\mathrm{S}$ indicates water caltrop starch, and the number indicates the cycles in cHMT. 

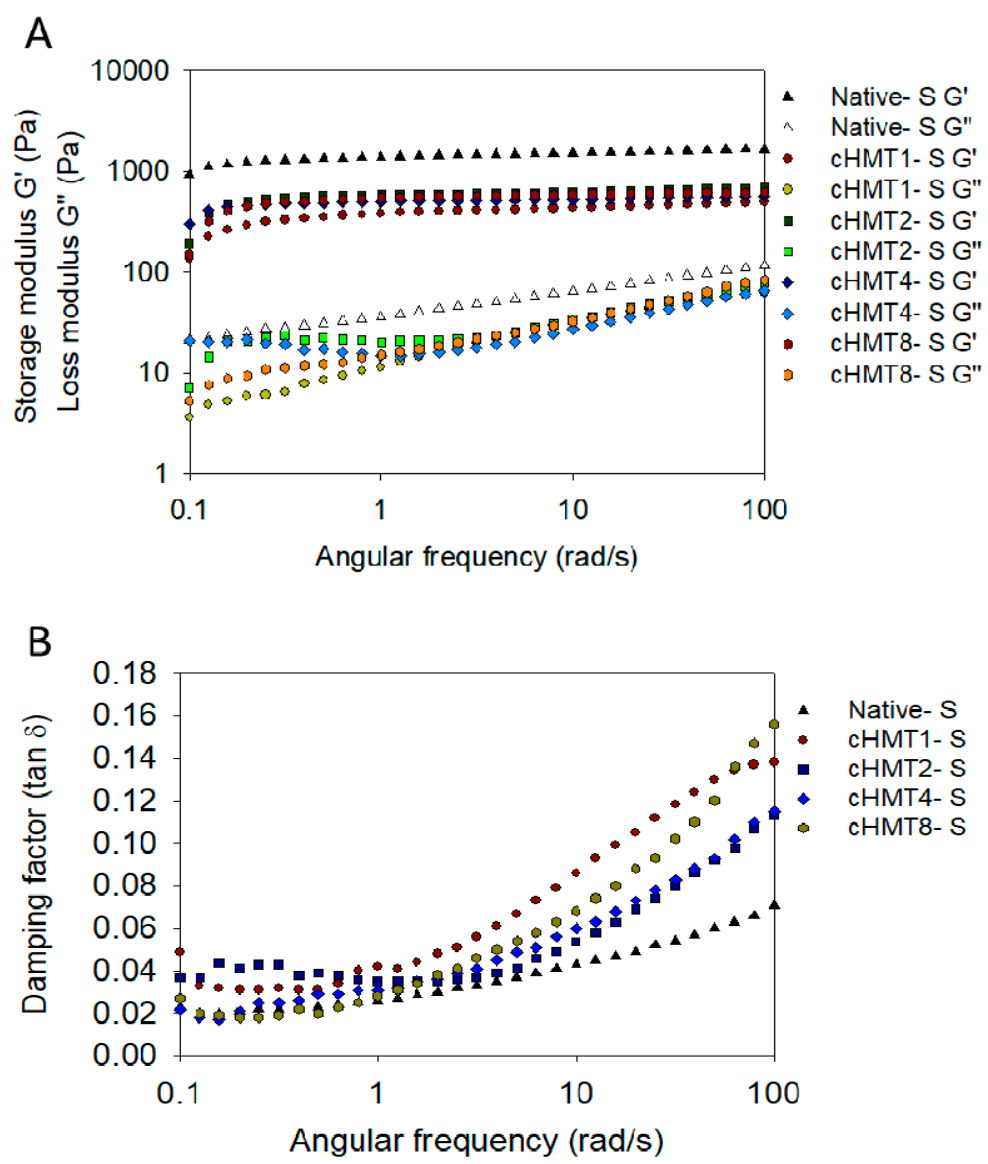

Figure 3. Dynamic rheological behavior of native and cHMT water caltrop starch. (A) Angular frequency dependence of $\mathrm{G}^{\prime}$ and $\mathrm{G}^{\prime \prime}$ at $25^{\circ} \mathrm{C}$ for starches; (B) angular frequency dependence of $\tan \delta$ at $25{ }^{\circ} \mathrm{C}$ for starches.

Tan $\delta$ can be used to describe the characteristics of the gel. When $\tan \delta$ is less than 1 , the material shows great elasticity; when the value of $\tan \delta$ is between 0.1 and 1 , it is classified as weak gel; and a $\tan \delta$ less than 0.1 shows strong gel characteristics. Tan $\delta$ of water caltrop starch ranged from 0.039 to 0.072 , which indicated strong gel properties. Furthermore, cHMT1-S showed the highest value, which may be explained by the strong disruption by a single cycle of cHMT.

\subsection{In Vitro Digestibility and Predicted Glycemic Index of Cooked Starch}

This experiment used the first-order model to simulate the final hydrolysis percentage $\left(\mathrm{HP}_{\infty}\right)$, hydrolysis rate $(\mathrm{k})$, hydrolysis index $(\mathrm{HI})$, and predicted GI value $(\mathrm{pGI})$. The sample hydrolyzed rapidly in the first $60 \mathrm{~min}$ and gradually slowed down with the extension of working time (Figure 4). 
In vitro digestibility of Native- $\mathrm{S}$
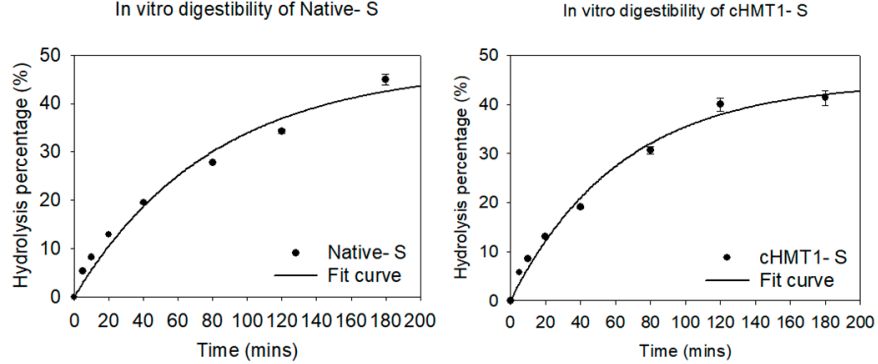

In vitro digestibility of CHMT8-
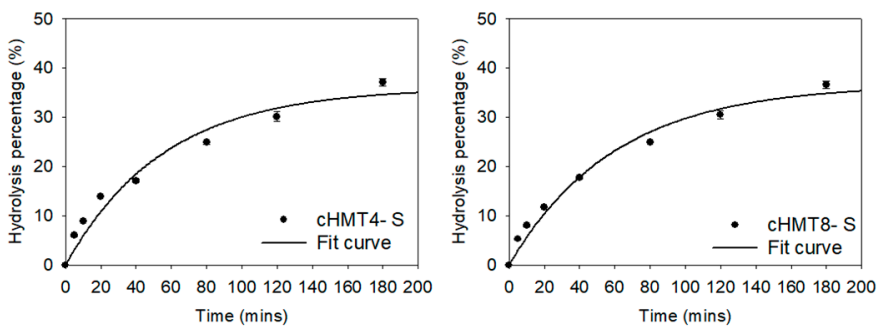

Figure 4. The hydrolysis curve of native and cHMT water caltrop starch.

As shown in Table 5, the $\mathrm{HP}_{\infty}$ of samples decreased significantly after modification; this may be due to the more ordered structure formed by repeated heating/cooling cycles in cHMT [23]. However, cHMT1-S with a single cycle of treatment had lower $\mathrm{HP}_{\infty}$, which may be ascribed to strong disruption to double helices and reduced formation of ordered structure, which resulted in more vulnerability to the enzyme.

Table 5. The digestibility of native and cHMT water caltrop starch ${ }^{1,2,3}$.

\begin{tabular}{ccccc}
\hline Treatment & HP $\infty \mathbf{( \% )}$ & $\mathbf{k} \times \mathbf{1 0}^{\mathbf{2}} \mathbf{( m i n}^{-\mathbf{1}} \mathbf{~}$ & HI & pGI \\
\hline Native-S & $46.13 \pm 0.52^{\mathrm{c}}$ & $1.42 \pm 0.20^{\mathrm{a}}$ & $79.71 \pm 0.53^{\mathrm{c}}$ & $83.47 \pm 0.28^{\mathrm{c}}$ \\
cHMT1-S & $44.58 \pm 2.22^{\mathrm{b}}$ & $1.59 \pm 0.13^{\mathrm{ab}}$ & $83.29 \pm 1.47^{\mathrm{d}}$ & $85.43 \pm 0.80^{\mathrm{d}}$ \\
cHMT2-S & $35.52 \pm 0.70^{\mathrm{a}}$ & $2.09 \pm 0.01^{\mathrm{c}}$ & $73.44 \pm 1.53^{\mathrm{b}}$ & $80.02 \pm 0.84^{\mathrm{b}}$ \\
cHMT4-S & $35.95 \pm 1.07^{\mathrm{a}}$ & $1.81 \pm 0.01^{\mathrm{b}}$ & $70.69 \pm 1.38^{\mathrm{a}}$ & $78.52 \pm 0.76^{\mathrm{a}}$ \\
cHMT8-S & $36.61 \pm 1.15^{\mathrm{a}}$ & $1.68 \pm 0.01^{\mathrm{b}}$ & $69.70 \pm 0.99^{\mathrm{a}}$ & $78.14 \pm 0.54^{\mathrm{a}}$ \\
\hline
\end{tabular}

${ }^{1}$ Data presented are in mean \pm SD form $(n=3)$; different letters in the same column indicate the significant difference at $p<0.05 .{ }^{2}$ The capital $S$ indicates water caltrop starch, and the number indicates the cycles in $\mathrm{cHMT}^{3} \mathrm{HP}_{\infty}$ indicates the equilibrium hydrolysis percentage, $\mathrm{k}$ indicates kinetic constant, $\mathrm{HI}$ indicates the hydrolysis index, and pGI indicates the predicted glycemic index.

In terms of digestion rate $(\mathrm{k})$, water caltrop starch increased slightly after modification. cHMT1-S showed greater pGI than Native-S, while the values of cHMT2-S, cHMT4-S, and cHMT8-S were significantly lower than Native-S, indicating that multiple cycles of heatmoisture treatment did reduce the digestibility of water caltrop starch. Lower digestibility may be affected by the amylose content. In previous studies, it was found that starch with a higher proportion of amylose showed lower digestibility and hydrolysis rate because the space occupied by amylose is smaller than that of amylopectin, so the structure of starch could be stacked tighter and not easily digested by enzymes [49-51]. In addition, crystalline type and relative crystallinity were also important factors affecting digestibility. Starch with higher relative crystallinity was more compact in structure, so enzymes were less likely to enter the starch granules [52].

\section{Conclusions}

This study showed that cHMT changed the in vitro digestibility, rheological properties, and physicochemical properties of water caltrop starch. The amylose content increased by modification due to the breakage of amylopectin which turned into small amylose fragments. The damaged starch content also significantly decreased in samples treated with an increased number of cycles because of recrystallized structure that expelled the 
testing enzyme. Single-cycle cHMT decreased the amylopectin peak in the GPC graph and lowered the weight-average molecular weight, but the weight-average molecular weight increased with multiple cycles because repeated cooling in cHMT may have promoted the integration of amylopectin, which had larger molecular weight. Better resistance to the heat and lower enthalpy needed for gelatinization was confirmed by DSC. Furthermore, modification gave water caltrop starch less shear-thinning behavior with higher $n$ value and lower gel-forming ability with lower $\mathrm{G}^{\prime}$ and $\mathrm{G}^{\prime \prime}$ values. After cooking, cHMT water caltrop starch treated with an increased number of cycles showed lower pGI, which could be explained by the increasing amylose content and more compact structure of starch granules, which led to better resistance to the enzymes. The simulated pGI test may not completely reflect the exact starch digestibility in vivo, and more research was needed to employ cHMT starch as ingredient for application. Such a study would provide a better understanding of the physicochemical properties, digestibility, and potential application of cHMT water caltrop starch, which may be a prospective alternative for common starch resources such as corn and potato.

Author Contributions: Conceptualization, L.-S.L.; methodology, L.-S.L. and P.-C.T.; validation, L.S.L. and P.-C.T.; formal analysis, P.-C.T.; investigation, L.-S.L. and P.-C.T.; resources, L.-S.L.; data curation, P.-C.T.; writing — original draft preparation, P.-C.T.; writing—review and editing, L.-S.L.; visualization, P.-C.T.; supervision, L.-S.L.; project administration, L.-S.L.; funding acquisition, L.-S.L. All authors have read and agreed to the published version of the manuscript.

Funding: This research was funded by the Ministry of Science and Technology in Taiwan under the grant number of MOST 108-2320-B-005-003-MY3.

Institutional Review Board Statement: Not applicable.

Informed Consent Statement: Not applicable.

Data Availability Statement: The data presented in this study are available on request from the corresponding author. The data are not publicly available due to ethical restriction and the intellectual property issue.

Acknowledgments: Sponsorship from the Ministry of Science and Technology in Taiwan is gratefully acknowledged.

Conflicts of Interest: There is none to declare.

\section{References}

1. Chiang, P.-Y.; Li, P.-H.; Huang, C.-C.; Wang, C.-C.R. Changes in functional characteristics of starch during water caltrop (Trapa Quadrispinosa Roxb.) growth. Food Chem. 2007, 104, 376-382. [CrossRef]

2. Chiang, P.-Y.; Li, P.-H.; Huang, C.-C.; Wang, C.R. Chemical composition and physical characteristics of water caltrop during growth. J. Sci. Food Agric. 2009, 89, 1298-1306. [CrossRef]

3. Singh, G.D.; Bawa, A.S.; Singh, S.; Saxena, D.C. Physicochemical, pasting, thermal and morphological characteristics of Indian water chestnut (Trapa natans) starch. Starch Stärke 2009, 61, 35-42. [CrossRef]

4. Wang, J.; Liu, T.; Bian, X.; Hua, Z.; Chen, G.; Wu, X. Structural characterization and physicochemical properties of starch from four aquatic vegetable varieties in China. Int. J. Biol. Macromol. 2021, 172, 542-549. [CrossRef] [PubMed]

5. Tran, P.L.; Lee, J.-S.; Park, K.-H. Molecular structure and rheological character of high-amylose water caltrop (Trapa bispinosa Roxb.) starch. Food Sci. Biotechnol. 2013, 22, 979-985. [CrossRef]

6. Zhu, F. Chemical composition, health effects, and uses of water caltrop. Trends Food Sci. Technol. 2016, 49, 136-145. [CrossRef]

7. Syed, F.N.N.; Zakaria, M.H.; Bujang, J.S.; Christianus, A. Characterization, functional properties, and resistant starch of freshwater macrophytes. Int. J. Food Sci. 2021, 2021, 8825970. [CrossRef]

8. Altemimi, A.B. Extraction and optimization of potato starch and its application as a stabilizer in yogurt manufacturing. Foods 2018, 7, 14. [CrossRef]

9. Saleh, A.; Mohamed, A.A.; Alamri, M.S.; Hussain, S.; Qasem, A.A.; Ibraheem, M.A. Effect of different starches on the rheological, sensory and storage attributes of non-fat set yogurt. Foods 2020, 9, 61. [CrossRef]

10. Cervini, M.; Gruppi, A.; Bassani, A.; Spigno, G.; Giuberti, G. Potential application of resistant starch sorghum in gluten-free pasta: Nutritional, structural and sensory evaluations. Foods 2021, 10, 908. [CrossRef]

11. Schafranski, K.; Ito, V.C.; Lacerda, L.G. Impacts and potential applications: A review of the modification of starches by heatmoisture treatment (HMT). Food Hydrocoll. 2021, 117, 106690. [CrossRef] 
12. Wolever, T.M.; Mehling, C. High-carbohydrate-low-glycaemic index dietary advice improves glucose disposition index in subjects with impaired glucose tolerance. Br. J. Nutr. 2002, 87, 477-487. [CrossRef] [PubMed]

13. Grgić, I.; Ačkar, Đ.; Barišić, V.; Vlainić, M.; Knežević, N.; Medverec Knežević, Z. Nonthermal methods for starch modification-A review. J. Food Process. Preserv. 2019, 43, e14242. [CrossRef]

14. Na, J.H.; Kim, H.R.; Kim, Y.; Lee, J.S.; Park, H.J.; Moon, T.W.; Lee, C.J. Structural characteristics of low-digestible sweet potato starch prepared by heat-moisture treatment. Int. J. Biol. Macromol. 2020, 151, 1049-1057. [CrossRef] [PubMed]

15. Lin, C.L.; Lin, J.H.; Lin, J.J.; Chang, Y.H. Progressive alterations in crystalline structure of starches during heat-moisture treatment with varying iterations and holding times. Int. J. Biol. Macromol. 2019, 135, 472-480. [CrossRef]

16. Suriya, M.; Reddy, C.K.; Haripriya, S. Functional and thermal behaviors of heat-moisture treated elephant foot yam starch. Int. J. Biol. Macromol. 2019, 137, 783-789. [CrossRef]

17. Khatun, A.; Waters, D.L.; Liu, L. A review of rice starch digestibility: Effect of composition and heat-moisture processing. Starch Stärke 2019, 71, 1900090. [CrossRef]

18. Zavareze, E.d.R.; Dias, A.R.G. Impact of heat-moisture treatment and annealing in starches: A review. Carbohydr. Polym. 2011, 83, 317-328. [CrossRef]

19. Ali, N.A.; Dash, K.K.; Routray, W. Physicochemical characterization of modified lotus seed starch obtained through acid and heat moisture treatment. Food Chem. 2020, 319, 126513. [CrossRef]

20. Yadav, B.S.; Guleria, P.; Yadav, R.B. Hydrothermal modification of Indian water chestnut starch: Influence of heat-moisture treatment and annealing on the physicochemical, gelatinization and pasting characteristics. LWT-Food Sci. Technol. 2013, 53, 211-217. [CrossRef]

21. Adawiyah, D.R.; Akuzawa, S.; Sasaki, T.; Kohyama, K. A comparison of the effects of heat moisture treatment (HMT) on rheological properties and amylopectin structure in sago (Metroxylon sago) and arenga (Arenga pinnata) starches. J. Food Sci. Technol. 2017, 54, 3404-3410. [CrossRef]

22. Wang, H.; Zhang, B.; Chen, L.; Li, X. Understanding the structure and digestibility of heat-moisture treated starch. Int. J. Biol. Macromol. 2016, 88, 1-8. [CrossRef] [PubMed]

23. Huang, T.-T.; Zhou, D.-N.; Jin, Z.-Y.; Xu, X.-M.; Chen, H.-Q. Effect of repeated heat-moisture treatments on digestibility, physicochemical and structural properties of sweet potato starch. Food Hydrocoll. 2016, 54, 202-210. [CrossRef]

24. Zhang, B.; Zhao, K.; Su, C.; Gong, B.; Ge, X.; Zhang, Q.; Li, W. Comparing the multi-scale structure, physicochemical properties and digestibility of wheat A- and B-starch with repeated versus continuous heat-moisture treatment. Int. J. Biol. Macromol. 2020, 163, 519-528. [CrossRef] [PubMed]

25. Lin, C.-L.; Lin, J.-H.; Lin, J.-J.; Chang, Y.-H. Properties of high-swelling native starch treated by heat-moisture treatment with different holding times and iterations. Molecules 2020, 25, 5528. [CrossRef]

26. Niu, W.; Pu, H.; Liu, G.; Fang, C.; Yang, Q.; Chen, Z.; Huang, J. Effect of repeated heat-moisture treatments on the structural characteristics of nanocrystals from waxy maize starch. Int. J. Biol. Macromol. 2020, 158, 732-739. [CrossRef] [PubMed]

27. Zhang, B.; Saleh, A.S.; Su, C.; Gong, B.; Zhao, K.; Zhang, G.; Li, W.; Yan, W. The molecular structure, morphology, and physicochemical property and digestibility of potato starch after repeated and continuous heat-moisture treatment. J. Food Sci. 2020, 85, 4215-4224. [CrossRef] [PubMed]

28. Wei, H.-X.; Liang, B.-D.; Chai, Y.-R.; Xue, L.-P.; Wang, X.-Q.; Yin, X.-M. Effect of different heat treatments on physicochemical properties and structural and digestibility of water caltrop starch. Starch Stärke 2020, 72, 1900275. [CrossRef]

29. Lutfi, Z.; Nawab, A.; Alam, F.; Hasnain, A.; Haider, S.Z. Influence of xanthan, guar, CMC and gum acacia on functional properties of water chestnut (Trapa bispinosa) starch. Int. J. Biol. Macromol. 2017, 103, 220-225. [CrossRef]

30. Tan, X.; Li, X.; Chen, L.; Xie, F.; Li, L.; Huang, J. Effect of heat-moisture treatment on multi-scale structures and physicochemical properties of breadfruit starch. Carbohydr. Polym. 2017, 161, 286-294. [CrossRef]

31. Song, Y.; Jane, J. Characterization of barley starches of waxy, normal, and high amylose varieties. Carbohydr. Polym. 2000, 41, 365-377. [CrossRef]

32. Kapoor, B.; Bhattacharya, M. Steady shear and transient properties of starch in dimethylsulfoxide. Carbohydr. Polym. 2001, 44, 217-231. [CrossRef]

33. Goñi, I.; Garcia-Alonso, A.; Saura-Calixto, F. A starch hydrolysis procedure to estimate glycemic index. Nutr. Res. 1997, 17, 427-437. [CrossRef]

34. Zhang, Y.; Zhang, Y.; Li, B.; Wang, X.; Xu, F.; Zhu, K.; Tan, L.; Dong, W.; Chu, Z.; Li, S. In vitro hydrolysis and estimated glycemic index of jackfruit seed starch prepared by improved extrusion cooking technology. Int. J. Biol. Macromol. 2019, 121, 1109-1117. [CrossRef]

35. Gao, H.; Cai, J.; Han, W.; Huai, H.; Chen, Y.; Wei, C. Comparison of starches isolated from three different Trapa species. Food Hydrocoll. 2014, 37, 174-181. [CrossRef]

36. Jiranuntakul, W.; Puttanlek, C.; Rungsardthong, V.; Puncha-arnon, S.; Uttapap, D. Amylopectin structure of heat-moisture treated starches. Starch Stärke 2012, 64, 470-480. [CrossRef]

37. Liu, C.; Hong, J.; Zheng, X. Effect of heat-moisture treatment on morphological, structural and functional characteristics of ball-milled wheat starches. Starch Stärke 2017, 69, 1500141. [CrossRef] 
38. Liu, C.; Song, M.; Liu, L.; Hong, J.; Guan, E.; Bian, K.; Zheng, X. Effect of heat-moisture treatment on the structure and physicochemical properties of ball mill damaged starches from different botanical sources. Int. J. Biol. Macromol. 2020, 156, 403-410. [CrossRef]

39. Pinto, V.Z.; Moomand, K.; Vanier, N.L.; Colussi, R.; Villanova, F.A.; Zavareze, E.R.; Lim, L.-T.; Dias, A.R.G. Molecular structure and granule morphology of native and heat-moisture-treated pinhão starch. Int. J. Food Sci. Technol. 2015, 50, 282-289. [CrossRef]

40. Bertoft, E.; Annor, G.A.; Shen, X.; Rumpagaporn, P.; Seetharaman, K.; Hamaker, B.R. Small differences in amylopectin fine structure may explain large functional differences of starch. Carbohydr. Polym. 2016, 140, 113-121. [CrossRef] [PubMed]

41. Kowittaya, C.; Lumdubwong, N. Molecular weight, chain profile of rice amylopectin and starch pasting properties. Carbohydr. Polym. 2014, 108, 216-223. [CrossRef] [PubMed]

42. Zhou, X.; Wang, R.; Yoo, S.-H.; Lim, S.-T. Water effect on the interaction between amylose and amylopectin during retrogradation. Carbohydr. Polym. 2011, 86, 1671-1674. [CrossRef]

43. Vandeputte, G.; Vermeylen, R.; Geeroms, J.; Delcour, J. Rice starches. I. Structural aspects provide insight into crystallinity characteristics and gelatinisation behaviour of granular starch. J. Cereal Sci. 2003, 38, 43-52. [CrossRef]

44. Gong, B.; Xu, M.; Li, B.; Wu, H.; Liu, Y.; Zhang, G.; Ouyang, S.; Li, W. Repeated heat-moisture treatment exhibits superiorities in modification of structural, physicochemical and digestibility properties of red adzuki bean starch compared to continuous heat-moisture way. Food Res. Int. 2017, 102, 776-784. [CrossRef]

45. Xie, Y.; Li, M.-N.; Chen, H.-Q.; Zhang, B. Effects of the combination of repeated heat-moisture treatment and compound enzymes hydrolysis on the structural and physicochemical properties of porous wheat starch. Food Chem. 2019, 274, 351-359. [CrossRef] [PubMed]

46. Khunae, P.; Tran, T.; Sirivongpaisal, P. Effect of heat-moisture treatment on structural and thermal properties of rice starches differing in amylose content. Starch Stärke 2007, 59, 593-599. [CrossRef]

47. Hernández-Centeno, F.; López-De la Peña, H.Y.; Hernández-González, M.; Rodríguez-González, C.A.; Tirado-Gallegos, J.M.; Rios-Velasco, C.; Zamudio-Flores, P.B. Physicochemical, thermal, rheological and morphological characteristics of flour and starch from a non-conventional source: Cucurbita foetidissima Kunth roots. J. Food Meas. Charact. 2020, 14, 1976-1985. [CrossRef]

48. Sandhu, K.S.; Siroha, A.K.; Punia, S.; Nehra, M. Effect of heat moisture treatment on rheological and in vitro digestibility properties of pearl millet starches. Carbohydr. Polym. Technol. Appl. 2020, 1, 100002. [CrossRef]

49. Xie, X.; Qi, L.; Xu, C.; Shen, Y.; Wang, H.; Zhang, H. Understanding how the cooking methods affected structures and digestibility of native and heat-moisture treated rice starches. J. Cereal Sci. 2020, 95, 103085. [CrossRef]

50. Singh, J.; Dartois, A.; Kaur, L. Starch digestibility in food matrix: A review. Trends Food Sci. Technol. 2010, 21, 168-180. [CrossRef]

51. Yee, J.; Roman, L.; Pico, J.; Aguirre-Cruz, A.; Bello-Perez, L.A.; Bertoft, E.; Martinez, M.M. The molecular structure of starch from different Musa genotypes: Higher branching density of amylose chains seems to promote enzyme-resistant structures. Food Hydrocoll. 2021, 112, 106351. [CrossRef]

52. Yu, B.; Li, J.; Tao, H.; Zhao, H.; Liu, P.; Cui, B. Physicochemical properties and in vitro digestibility of hydrothermal treated Chinese yam (Dioscorea opposita Thunb.) starch and flour. Int. J. Biol. Macromol. 2021, 176, 177-185. [CrossRef] [PubMed] 